\section{Predictable outcome}

\section{Philip Gummett}

Research Foresight: Priority-Setting in Science. By Ben R. Martin and John Irvine. Pinter, London:1989. Pp.366. £35, \$45.

In his New Atlantis, Francis Bacon describes the order or society called Salomon's House. This seventeenth-century prototypical research organization operated a well-planned division of labour. Some of the fellows surveyed the literature; others devised or performed experiments; yet others explored the theoretical implications of research results; and some (called 'Benefactors') sought applications of this work. Another important role was performed by those who travelled abroad, in disguise, to collect the books and experiments of other countries. These were called Merchants of Light.

Today, when the state demands increasing returns from its investment in science (so that the 'Benefactors' might be renamed 'Exploiters'), Bacon might think it wise to add a cadre of policy analysts. They would need their own Merchants of Light, for science policy is now an international business. Two candidates might be the authors of the book under review, who have travelled the world, in the guise of contractors to the Dutch government, bringing back information on how eight countries engage in 'foresight' in science and technology. Oddly, having gone to France, West Germany, the United States, Japan, Australia, Canada, Sweden and Norway, they omit their own country, Britain. Their excuse (lack of time and difficulties over commenting on foresight exercises in which they had been involved) is not entirely compelling.

'Foresight' is a slightly curious term. For one thing, what should we call the people who do it? 'Foreseers' sounds too biblical, while 'forecasters' misses a crucial distinction. As the authors explain, the aim is not to forecast, nor - as was suggested by the subtitle of their previous book, Foresight in Science: Picking the Winners, published by Pinter in 1984 - to pick winners. Rather, it is to establish a continuous process for reaching an improved understanding of possible developments in science and technology, and the forces likely to shape them, in an attempt to nurture winners and hence create the future.

In their travels, Martin and Irvine encountered a great deal of activity of these types, expecially in relation to strategic and applied research (less so for basic research). There were, though, considerable variations between countries in terms of methods and institutions used, and commitment to the foresight process. Some countries use formal bibliometric methods to try to spot growth points in science, nationally and internationally. Some engage in elaborate consultative exercises, involving large numbers of scientists and users of science and technology. Some adapt various tools from the kitbag of forecasters and futurologists. Some set up specialist panels on narrow subjects, while others try to take a view of the whole national scene. Some draw on professional analysts (especially Japan, which has a network of some 300 public and private think-tanks, many of them with levels of expertise that are unmatched even by the large US consultancies). Some use what a respondent in the

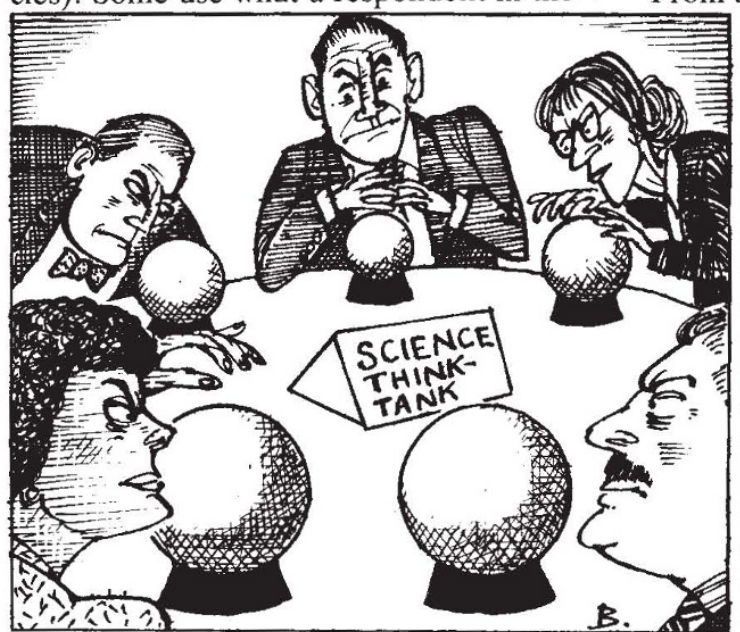

research, even in Japan. Second, the authors show the importance of trying to integrate the different levels of the policy process, from all-embracing national socio-economic goals, down through various sectoral institutions and objectives, to strategic and basic research. But they also show the crucial importance, in seeking this integration, of achieving a balance between the views of innovative young scientists, who can see the possible directions in which science might go, and the more seasoned views of senior officials, industrialists and other users, who can relate science-push to social demand, particularly across the boundaries of established disciplines.

From a parochial angle, it is a pity that Britain was excluded from the study. Britain is a country in which formal foresight methods of a bibliometric type have been used by, for example, the Royal Society and the Advisory Board for the Research Councils. The Cabinet's Advisory Council on Science and Technology, and its predecessor, have conducted a number of studies with the intention of guiding policy over research priorities. The University Grants Committee, now the Universities Funding Council, has engaged in substantial restructuring of basic research, though without (as far as one can tell) any United States called the BOGSAT method (Bunch of Guys Sitting Around a Table).

What lessons can be extracted from this bewildering variety? The DirectorGeneral for Science Policy of the Dutch Ministry of Education and Science, in introducing the book, singles out three. First, analysis of long-term needs and opportunities for research should be part of a well-planned process that includes implementation of the choices made. The authors identify a number of attempts at foresight that failed because it was not clear from the outset what was to be done with the results. Second, it is essential, especially for smaller countries, to carry out systematic global monitoring of developments in research. This is something that the Japanese have been doing since the 1950s. Third, and as already indicated above, the aim of policy should be to nurture scientific winners rather than simply to try to pick them, readymade as it were. That is, a process of identifying, and then supporting, areas deemed to be of national importance should be established.

Other lessons include, first, the point that introducing foresight approaches can be a slow and painful process, especially in countries with no culture of planning or consensus-seeking. This is particularly so in relation to setting priorities in basic vision of the national future that it is aiming to create. And, in response to the arguments in Irvine and Martin's 1984 book, the Centre for Exploitation of Science and Technology - which is mainly funded by industry - has been set up to try to articulate industrial views of the future and integrate them with government policy. The views of our Merchants of Light on these measures would have been welcome.

We can be sure that foresight is here to stay (which may make it worth trying to find a better name for it). The perception is growing that the procedure does not imply draconian planning. Instead it aims at improving communications between producers and users of research and arriving at decisions based on a consensus about the choices to be made. The winners, so the advocates of foresight claim, will be the countries that manage this process best.

Philip Gummett chairs the Board of Science and Technology Policy, University of Manchester, Manchester M13 9PL, UK.

- Recently published by Routledge, London, is Innovation and Technology Transfer in Japan and Europe: Industry-Academic Interactions, by Glyn O. Phillips. The book provides "a perspective against which we [the British] can take decisions about the future of our own industry-education interaction arrangements" and costs $£ 45$. 